\title{
UM OLHAR SOBRE AS PESQUISAS ROMENAS EM HISTÓRIA DA TRADUÇÃO
}

\author{
A LOOK AT ROMANIAN RESEARCH INTO THE HISTORY OF TRANSLATION
}

\author{
UN REGARD SUR LES RECHERCHES ROUMAINES EN HISTOIRE DE LA \\ TRADUCTION
}

\author{
(a) \\ Georgiana LUNGU-BADEA* \\ Universidade do Oeste de Timisoara \\ Timișoara, Timiş, Romênia \\ Universidade de Brasília \\ Brasília, Distrito Federal, Brasil \\ Traduzido por*: \\ Natália Oásis de OLIVEIRA*** \\ Universidade de Brasília \\ Brasília, Distrito Federal, Brasil
}

Resumo: Neste artigo, pretendemos apresentar um panorama da história e historiografia da tradução em romeno, no conjunto das múltiplas abordagens das quais a história da língua, a história da literatura e história das práticas artísticas e culturais podem ser objeto. Para fazer este sobrevoo, estabelecemos como referências: a tradução como ato, os atores da tradução (parcialmente elencados em listas e/ou indiretamente ordenados em dicionários e listas de obras traduzidas) e a tradução como resultado. Nossa intenção é destacar a utilidade das pesquisas em história da tradução romena, que servem principalmente para revelar o papel que a tradução tem desempenhado na autodeterminação linguística e administrativa e, consequentemente, na construção do passado nacional.

Palavras-chave: Tradução(ões). Tradutores. História da tradução em romeno/da língua romena. Historiografia da tradução.

Abstract: This article sets out to offer a panoramic view of the history and historiography of translation into Romanian from a variety of approaches, among them the history of language, of literature, and of cultural and artistic practices. The following aspects will be focused on in carrying out this survey: translation as an act, the participants in the translation process (partially recorded in indexes and/or indirectly listed in dictionaries and indexes of translated works), and translation as a result. Our intention is to emphasize how valuable research in the field of Romanian translation is, in particular in order to reveal the role translation has played in the process of linguistic and administrative self-determination, and, through this, in the construction of the national past.

Keywords: Translation(s). Translators. History of translation into/from Romanian. Historiography of translation.

Résumé : Dans cet article, nous nous proposons de présenter un panorama de l'histoire et de l'historiographie de la traduction en roumain, dans le concert des multiples approches dont l'histoire de la langue, l'histoire de la littérature et l'histoire des pratiques artistiques et culturelles peuvent faire l'objet. Pour réaliser ce survol, nous avons établi comme repères : la traduction comme acte, les acteurs de la traduction (partiellement recensés dans des répertoires et/ou indirectement ordonnés dans des dictionnaires et répertoires des oeuvres traduites) et la traduction comme résultat. Notre intention est de mettre en avant l'utilité des recherches en histoire de la traduction roumaine, qui servent principalement à révéler le rôle que la traduction a joué dans l'autodétermination linguistique et administrative et, par cela, dans la construction du passé national. 
Mots clés : Traduction(s). Traducteurs. Histoire de la traduction en roumain/de la langue roumaine. Historiographie de la traduction.

RECEBIDO EM: 10 de novembro de 2019

ACEITO EM: 30 de novembro de 2019

PUBLICADO EM: abril 2020

\section{Introdução}

$\mathrm{N}$

a Romênia, podemos falar sobre o início de uma disciplina científica, a historiografia da tradução, baseada em pesquisas sobre história da tradução e no modelo de continuidade temporal (a enumeração das traduções, descrição cronológica das traduções, dos tradutores) em que a periodização é emprestada da história da língua e/ou da literatura romena. A isso acrescenta-se uma reflexão sobre a metalinguagem da tradução (estratégias, processos, métodos, conceitos etc.) e as visadas da pesquisa em história e, em seguida, em historiografia da tradução.

A reflexão que propomos nas páginas seguintes, bem geral, é apenas um esboço de uma historiografia da tradução em romeno. Os limites que isso acarreta derivam tanto do fato de que a história da tradução em romeno ainda não alcançou seu ápice, quanto da dificuldade de inventariar fontes impressas e eletrônicas. Contudo, nas pesquisas romenas em história da tradução examinadas, foi possível identificar pontos de referência segundo os quais concordase tacitamente em encarar a história da tradução em romeno. Essas observações, bem ancoradas na história nacional e na cultura romena, na evolução da língua e literatura romenas, são complementadas pela apresentação de contatos livrescos (leitura de textos originais e textos traduzidos) e não livrescos, diretos ${ }^{1}$ e indiretos ${ }^{2}$.

Consequentemente, observa-se a defasagem que há entre as duas histórias: "a história interna", vivida e escrita "pelos que a produzem", e "a história externa", "elaborada retrospectivamente por pesquisadores modernos" (D'HULST, 2014, p. 17). Embora esta defasagem seja clara, os pesquisadores romenos respondem apenas rara e, em geral, implicitamente a perguntas como: "para que (quem) serve a história da tradução?”, "é necessário encarar uma história geral da tradução - 'dos grandes panoramas internacionais' (DELISLE, 1998, p. 21-43) - na qual a história nacional encontra une/seu lugar?”, ou “é necessário, primeiro, elaborar uma história nacional das traduções/da tradução/dos tradutores?". 
Ao considerarmos amplamente o campo da tradução, ficamos tentados a tratar imparcialmente os eixos das pesquisas históricas, historiográficas e meta-historiográficas (cf. D'HULST, 2014, p. 22). Propomos, para este esboço historiográfico, balizas - a tradução, as traduções e os tradutores - que podem permitir: a identificação das conexões que se instauram entre as teorias indutivas da tradução (dos séculos XVIII e XIX), o empréstimo de modelos teóricos do Ocidente as teorias linguísticas dedutivas; a análise da relação entre história e historiografia, teoria e prática da tradução.

\section{A historiografia da tradução em romeno}

$\mathrm{Na}$ Romênia, o trabalho de historiador e/ou de historiógrafo é realizado por pesquisadores que vêm de diferentes horizontes tradutivos: professores de tradução/literatura (GRIMM [1916-1943] 2012; JACAS, 1991), críticos da tradução, tradutólogos. Alguns pesquisadores se interessam pelo papel que a tradução tem desempenhado na história dos romenos e por sua contribuição para a compreensão da história, papel que ela não cessa de cumprir; alguns visam a análise histórica dos métodos e formas de tradução e, finalmente, outros se esforçam para retratar tradutores ${ }^{3}$ e para estudar as condições nas quais estes trabalharam. A periodização histórica varia de uma pesquisa para outra, conforme os pesquisadores levam em conta as histórias da língua e/ou da literatura romena ${ }^{4}$, as línguas traduzidas $^{5}$, as correntes ${ }^{6}$ e os gêneros literários traduzidos ${ }^{7}$ etc. Recentemente, pôde-se constatar uma tendência não somente em ressaltar e explicar antigos métodos de tradução, mas também em desenvolver métodos cronológicos, temáticos, genéricos etc., e instrumentos específicos de pesquisa ${ }^{8}$ para a historiografia da tradução.

A maneira como a tradução influenciou na formação da língua literária romena e na criação da literatura romena já vem sendo objeto de estudo de obras inteira ou parcialmente consagradas ao peso que ela teve na compreensão e na determinação de diferentes fenômenos históricos. Os historiadores da língua romena foram os primeiros a se dedicarem ao estudo da tradução, e, assim, a historiografia do romeno se estabeleceu. Suas abordagens facilitaram a compreensão da tradução como um fenômeno e de suas relações com outras atividades artísticas e educacionais, políticas e administrativas; elas também abriram o caminho para abordagens estritamente históricas da tradução, das quais estamos tentando fazer um primeiro esboço historiográfico. 


\subsection{Observações sobre a história da tradução em romeno e os behavioremas (comportamentos) dos tradutores}

Uma série de pesquisas romenas em história da tradução sucedem cronologicamente os eventos da história geral e interpretam seu significado na prática da tradução. Assim, a recepção e a influência das ideias europeias foram determinantes para a história dos romenos. Grandes momentos e atos, estudados em relação à tradução, ajudaram a entender a evolução da língua, da cultura e da sociedade romenas, a medir seu impacto no progresso e a construir a história desse povo. Trata-se, portanto, das pesquisas que adotaram a cronologia dos acontecimentos e estimaram o impacto que as reformas escolares de 1770 e 1790 tiveram sobre a tradução; a criação das escolas onde o ensino era em romeno; a declaração do alemão como língua oficial na Transilvânia, o que levou à institucionalização do bilinguismo romeno-alemão (1795); a participação dos boiardos romenos bilíngues nativos (greco-romanos) no renascimento do helenismo; da revolução de Tudor Vladimirescu, em 1821; o Tratado de paz de Adrianópolis (1829); a passagem para o bilinguismo franco-romeno, após o Regulamento orgânico (1831 na Moldávia, 1832 em Valáquia); a revolução romena de 1848; a união da Moldávia e da Valáquia

134 (1859). Nestas circunstâncias, direta e indiretamente, literaturas e conhecimentos de fora penetraram na língua e a cultura romenas (IORGA 1907-1909; PIRU 1977; GHEŢIE 1978; IVĂNESCU 1980; MUNTEANU; TÂRA [1978] 1983).

O estudo histórico do processo tradutivo mostra que as traduções-resultados emergem de diferentes epistemes e que, para fazer o panorama da história e historiografia da tradução romena, é necessário partir do contexto político e econômico, por um lado, e o contexto científico, literário e artístico, por outro. As relações culturais, interculturais e transdisciplinares determinaram o paradigma tradutivo e as mudanças que ele sofreu sob a influência de tendências externas e internas variadas (PHILIPPIDE 1888; LOVINESCU 1926-1929; CĂLINESCU 1941; IVAŞCU 1968; CIOCULESCU 1973). Assim, historiógrafos foram levados a questionar as visadas presumíveis do historiador e sua reflexão sobre a metalinguagem histórica e, posteriormente, a estabelecer a relação entre a concepção tradutiva do passado e a do presente (GRIMM [1916-1943] 2012; URSU 1962; MUNTEANU 1995; LORÍA-RIVEL 2004; LUNGU-BADEA 2007, 2008, [2013] 2015a, 2017; LENZ 2011; GAFTON 2012). Finalmente, eles mostraram que as reflexões descritivas, bem como as teorias linguísticas (latinismo, purismo, italianismo) e a intenção de padronizar a língua romena e a tradução para romeno representam os méritos da pesquisa em história da tradução na Romênia. É graças ao ato de deshistorização que foi possível, primeiro, traçar os eixos do pensamento 
prototradutológico romeno, em seguida, identificar e estudar as raízes e razões do desenvolvimento atual da tradutologia na Romênia, e, por último, propor um esboço da historiografia da tradução e as traduções em romeno (LUNGU-BADEA, [2013] 2015a).

Numa outra vertente da historiografia da tradução, situam-se a análise de prefácios, dos discursos dos tradutores (GAFTON, 2012; GIURGINCA, 2012) e de textos traduzidos (IORGA 1936; ANGHELESCU 1972, 1974; BARBU 1987), a tradução comparada, as monografias centradas em tradutores e obras traduzidas (GHEŢIE; MARES 1996; ISAR 2003; CAMARIANO 1946; URSU 1994; LUNGU-BADEA, 2017; BADEA 2019), em escritores traduzidos para o romeno ${ }^{9}$, ou autores romenos traduzidos para outras línguas ${ }^{10}$.

Estas pesquisas e muitas outras, que os limites espaciais deste artigo nos impedem de aqui citar, puderam contextualizar os problemas e dificuldades com os quais depararam-se os tradutores; mostrar as correlações que existem entre os discursos, os objetivos e os instrumentos dos tradutores romenos de antigamente e de hoje. Foi possível constatar divergências (causadas, obviamente, pela diferença temporal e a diferença intra e interlinguística) e semelhanças entre os behavioremas (comportamentos) tradutivos e prototradutológicos dos tradutores romenos e dos tradutores ocidentais, indo dos métodos às estratégias e procedimentos (LUNGU-BADEA [2013], 2015a, 2015b).

Monografias, mais raras, e perfis de tradutores, artigos de dicionários sobre os tradutores, fazem parte da complexidade da historiografia romena da tradução. Os pesquisadores romenos analisaram a maneira dos tradutores de contribuir para a introdução de escritores estrangeiros, oferecer modelos aos escritores autóctones, popularizar os saberes, formar o gosto do público-alvo romeno e educá-lo. Eles mostraram que, independentemente do status dos autores traduzidos (de anônimos, comuns ou notórios e, portanto, reconhecidos e/ou criticados), os tradutores também se alimentam da glória dos autores traduzidos. Assim, podese constatar que no espaço de recepção do romeno-alvo, a fama do tradutor é ou imanente (Beldiman, Heliade Radulescu, Spartali, Marcovici), ou resultante da fama da qual goza o autor traduzido $^{11}$.

\subsection{Visões sobre as pesquisas em história das traduções}

Quando se trata da história da tradução (ato, fenômeno), encara-se inevitavelmente a história das traduções e dos tradutores e da sociedade em que acontece o ato tradutório. No entanto, não se trata apenas de descrever os textos traduzidos e as maneiras de colocá-los em romeno, mas sim de surpreender os fatos, os atos, as situações em sua evolução, a fim de melhor 
apreendê-los e apreciar. Os pesquisadores insistem tanto na novidade das traduções - para a época e para o destinatário - quanto em sua filiação (PHILIPPIDE 1888; CĂLINESCU 1941; MUNTEANU; TARA, 1983; MUNTEANU, 1995). Por isso, a necessidade de fazer a história da tradução e de, em seguida, ensiná-la para que ela seja conhecida pela complementaridade das relações que estabelece com a história da língua romena e com a história dos romenos e da sua relação com outros povos (IORGA, 1917; CAMARIANO, 2008). Graças à tradução, seguimos o cumprindo as aspirações nacionais, administrativas políticas, literárias e estéticas; graças às traduções, formamos o gosto dos leitores e os educamos; pela história e pela historiografia da tradução, aprendemos a preparar melhor o futuro da língua romena, e a preservar a sua identidade por meio da tradução.

A comparação da história dos tradutores romenos e da história das traduções romenas, mostra que a segunda é melhor articulada. Permitindo compreender a gênese da literatura romena, as traduções literárias foram inventariadas em vários tipos de obras: dicionários (da literatura romana, 1979, do romance traduzido em romeno, 2005); listas de traduções e tradutores (RTR I e RTR II 2006), bibliografias de obras literárias traduzidas para o romeno 136 (FECIORU 1937; REISCHEL 1957; GEAMBAȘU (coord.), 2011). Este escopo de tradução está na origem da atenção particular que os pesquisadores deram às relações entre a literatura romena e outras literaturas, registradas nos sete volumes da bibliografia das relações estabelecidas entre literatura romena e literatura estrangeira em periódicos (1980-1985 e 19972002). Apesar da falta de concordância existente entre o aparecimento e a evolução da literatura romena e as literaturas ocidentais, a sua gênese não difere da gênese de outras literaturas em línguas nacionais (a tradução em romeno como gênero literário, prática emprestada à França onde conheceu a sua grandeza e a sua decadência, iria percorrer o mesmo caminho).

Os historiadores ${ }^{12}$ da língua romena esboçaram indiretamente a história da tradução; poder-se-ia ler, de maneira indireta, a história da língua romena como história da tradução em romeno. No século XIX, os letrados romenos eram numerosos, historiadores, gramáticos e tradutores que enxergavam a tradução como uma ferramenta para o enriquecimento da língua romena e, por conseguinte, para sua normalização (cf., por exemplo, Heliade Rădulescu [1828] 1980, XXVII-XXVIII). Havia, sob a influência do nacionalismo europeu, um meio de contribuir para a afirmação da nação romena. A exemplo dos historiadores da língua romena, os pesquisadores que se interessam pelo estudo histórico da tradução, da terminologia ${ }^{13}$, ressaltam seja implicitamente, seja explicitamente, a apetência do romeno, uma língua ainda jovem no século XIX, para a criação autêntica, sua ânsia de seguir os passos das grandes 
culturas (COSCO 1934; IORGA 1936; CAMARIANO 1946; NICOLESCU 1958; ANGHELESCU 1974; BARBUDO 1987; URSU 1994; MUNTEANU 1995; LENZ 2011) e de afirmar, por último, a sua autonomia de criação e a sua originalidade (LUNGU-BADEA, [2013] 2015a, 2015b).

As histórias da língua e da literatura romena, os escritos consagradas a letrados dos séculos XVI - XIX, as análises filológicas dos textos traduzidos (MORARU, 1996; ANGHELESCU, 1974; ISAR, 2003; URSU, 1999) permitem estabelecer a filiação das ideias, atestar a afiliação dos tradutores, destacar a complementaridade das abordagens exploradas pelo historiador da tradução, que tenta recuperar a relação entre as aspirações e os interesses políticos, nacionais e administrativos, por um lado, e os ideais linguísticos e literários, por outro. Às vezes conflituosos, os ideais linguísticos, certamente complementares, serviram "à ambição de organizar o governo a fim de obter a autodeterminação política e administrativa, e ao desejo de forjar um único instrumento de comunicação para chegar à autodeterminação linguística" (LUNGU-BADEA, 2011, p. 42-43; BADEA, 2019, p. 77-97). Eles também formaram os principais eixos das ações de políticos, historiadores e escritores dos séculos XIX e XVI, como Gh. Asachi, I. Heliade Rădulescu, Alecu Russo, George Bariţiu e Titu Maiorescu.

$\mathrm{O}$ estudo histórico das traduções permitiu estabelecer um paralelo, tão desejado pelos letrados romenos do século XIX, entre suas aspirações e aquelas dos letrados e tradutores franceses do século XVIII. Sem se aprofundar nas tendências em uso na França, interessandose menos pela universalidade do pensamento (de acordo com a acepção veiculada à época: o extralinguístico e, por conseguinte, independente da língua na qual esta foi formulada) e pela restituição do pensamento-fonte, das ideias do autor, com a ajuda dos meios que o romeno-alvo dispõe, os tradutores compreenderam intuitivamente e colocaram em prática o princípio de traduzir como se o autor tivesse escrito em romeno. O discurso - fragmentos de teoria - sobre as técnicas de traduzir, une justificação das escolhas tradutivas e invocação à clemência dos leitores perante os eventuais erros de tradução. A análise dos prefácios que acompanham as traduções (GAFTON, 2012; GIURGINCA, 2012; Un capitol de traductologie românească [Um capítulo de tradutologia romena], 2008; Lungu-Badea, [2013] 2015a) prova a utilidade da pesquisa histórica e da abordagem de pesquisa descritiva e comparada que contribuem para esclarecer um aspecto insuficientemente estudado, mas significativo para compreender a dinâmica coerente da literatura e da língua romena. Para além dos desafios políticos e linguísticos da tradução, os pesquisadores consideram também a preocupação dos tradutores com a estética. Uma vez que a tradução foi orientada principalmente para o leitor-alvo, a estética 
está centrada na recepção em romeno-alvo. As expectativas do leitor, reais ou atribuídas, influenciam os objetivos e os instrumentos de tradução (LUNGU-BADEA, 2008, p. 259-270). Chega-se a esta conclusão após a análise das traduções e os discursos prefaciais que as acompanham. O destino dos prefácios que acompanham as traduções em romeno é similar ao destino dos prefácios escritos no Ocidente, mas pouco conhecido como tal. Estes prefácios, que se assemelham aos prefácios de Oresme (para a tradução dos tratados de Aristóteles), John Dryden (para a tradução das Epístolas de Ovídio, 1680), poderiam adquirir o estatuto de "pequeno tratado de tradução". Os seus ecos, funções e efeitos confirmam-no. Posições absolutas e contraditórias, orientadas para a língua romena ou para as línguas traduzidas, vêm na esteira dos escritos de Heliade Rădulescu, Bariţiu, Kogălniceanu, Maiorescu etc. A política linguística e o interesse comercial dos editores agiram na empreitada de padronização romena e no estabelecimento de uma norma supradialetal dos diferentes dialetos romenos. O estudo dos discursos sobre a tradução assinalou explicitamente a existência de dois aspectos: primeiro, uma crítica dura às escolhas superficiais e aleatórias dos escritores menores ou obscuros traduzidos em romeno, e, por conseguinte, um apoio para a criação autêntica (teatro, etc.), sem marcas de estrangeirismo. Os argumentos invocados voltam a dizer, em suma, que a língua romena estava carregando uma virtualidade cuja concretude teria se tornado visível por um duplo movimento de apagar a rusticidade do vocabulário de obras autênticas, por um lado, e de importar modelos melhores (franceses, italianos, alemães), por outro. Essas são as principais razões que levaram Kogălniceanu a publicar em Dacia literară um apelo para limitar o número de traduções (KOGĂLNICEANU, [1840-1844] 1956). Ele criticou a má escolha dos textos a traduzir (CORNEA, 1966, p. 51-54) e exigiu que não se procedesse à tradução de uma obra antes que se houvesse decidido a utilidade da sua tradução para a cultura romena. Condenou violentamente as imitações que "matava[m] o espírito nacional” (KOGĂLNICEANU, [1840] 1956, p.135), a ideia de parasitismo do gênio nacional que é retomada no manifesto que publicou na revista Propăşirea ([Progresso], 1844). Incentivou, no entanto, a tradução de obras essenciais que considerava indispensáveis para o progresso social dos romenos, como o Espírito das leis de Montesquieu, as obras de Demóstenes, Xenofonte, de Tucídides, ou a tradução de textos legislativos. A análise dos discursos sobre a tradução assinala a existência e a prática dos dois métodos tradicionais de tradução que são testemunha da existência da tradução universal: um método/maneira centrada na letra e orientada para a língua-fonte, o outro no espírito, no leitor-alvo e/ou na língua-alvo. 
A história da história da tradução, a historiografia, permite, em primeiro lugar, fixar pontos cruciais na evolução e a prática tradutória e pontos de comparação entre as etapas da história da tradução no Ocidente e a história da tradução em romeno, em segundo lugar, valorizar o passado tradutivo, a reflexão tradutiva na qual se funda a atual pesquisa em tradutologia.

\section{Conclusão}

Sem pretendermos nos situar na temporalidade do tradutor/da tradução, nem na temporalidade dos contemporâneos da pesquisa histórica, tentamos administrá-los e esperamos que as balizas estabelecidas aqui sirvam para desenvolver uma historiografia da tradução em romeno. A fim de facilitar a compreensão das experiências do passado, seguimos a apreender e demonstrar a historicidade dos fatos tradutivos, reflexões sobre os discursos dos tradutores. Assim, apoiamo-nos nelas e criamos o contexto favorável para que o leitor contemporâneo conheça a alteridade dos tradutores e dos leitores do passado. Se o tradutor é um contrabandista de palavras, o historiador é um contrabandista de fatos, ações; ambos tornam mais fácil a tarefa dos leitores que tentam relacionar o passado com o presente, entre alhures e aqui. Assim, a história da tradução pode esclarecer o passado, a historiografia da tradução, o presente e o futuro.

\section{REFERÊNCIAS}

ANGHELESCU, Mircea. Observaţii cu privire la traducerile româneşti din Halima în secolul al XVIII-lea [Remarques sur les traductions roumaines d'Halima - XVIIIe siècle]. In: Limba Română, v. XXIII, nr. 1: 25-28, 1974.

ANGHELESCU, Mircea. Prima traducere românească din Halima [Premiere traduction roumaine d'Halima]. Limba Română, v. XXI, n. 3, p. 262-266, 1972.

BARBU, Violeta. Cele mai vechi traduceri din Voltaire. Limba română, v. (I), 36, n. 6, p. 525-535, 1987.

BADEA, Georgiana I. Traduction (s) et paradigmes de lecture: étude des formes de réception de la littérature française traduite en langue roumaine $-\mathrm{XVIII}^{\mathrm{e}}-\mathrm{XIX}{ }^{\mathrm{e}}$ siècles. In: Au cour de la traductologie. Hommage à Michel Ballard. Etudes réunies par L. D'hulst, M. Mariaule, C. Wecksteen-Quinto. Arras: Artois Presses Université, 2019. p. 77-97.

\section{BADEA, Georgiana I. Bibliografia relaţiilor literaturii române cu literaturile străine în} periodice (1859-1918) Bibliographie des relations de la littérature roumaine avec les littératures étrangères], vol. I-III, lucrare coordonată de Ioan Lupu şi Cornelia Ştefănescu, Editura Academiei R.S.R, 1980-1985. 
BADEA, Georgiana I. Bibliografia relaţiilor literaturii române cu literaturile străine în periodice (1919-1944) [Bibliographie des relations de la littérature roumaine avec les littératures étrangères], v. IV-VII, Institutul de Istorie şi Teorie Literară „George Călinescu”, autori: Ana - Maria Brezuleanu, Ileana Mihăilă, Viorica Niscov, Michaela Şchiopu, Cornelia Ştefănescu, prefaţă de Dan Grigorescu, Bucureşti, Editura Academiei Române,1997-2002.

BADEA, Georgiana I. Bibliografia traducerilor din literaturile slave (1945-2011) [Bibliographie des œuvres littéraires slaves traduites en roumain]. Geambașu, Constantin (coord.). Bucureşti: Editura Universităţii din București, 2011.

CAMARIANO, Ariadna. Spiritul revoluţionar francez şi Voltaire în limba greacă şi română [L'esprit révolutionnaire français et Voltaire dans les langues grecque et roumaine]. Bucureşti : Tiparul «Cartea românească», 1946.

CAMARIANO-CIORAN, Ariadna. Relaţii româno-elene: studii istorice şi filologice (secolele XIV - XIX) [Relations gréco-roumaines. Études d'histoire et de philologie (XIVe XIXe siècles)]. Bucureşti : Editura Omnia, 2008.

CĂLINESCU, George. Istoria literaturii române dela origini până în prezent [Histoire de la littérature roumaine, des origines à nos jours]. Bucureşti: Fundația pentru Literatură și Artă, 1941.

140 CIOCULESCU, Şerban. Istoria literaturii române. Epoca marilor clasici prezent [Histoire de la littérature roumaine. L'Époque de grands classiques]. Bucureşti: Editura Academiei, 1973.

CORNEA, Paul. De la Alexandrescu la Eminescu. Aspecte-Figuri-Idei. Bucureşti : Editura pentru Literatură, 1966.

COSCO, Olga. Primele cărţi franceze traduse în româneşte. Istoria lui Carol XII de Voltaire [Les premiers livres français traduits en roumain. L'Histoire de Charles XII de Voltaire].

Cercetari literare. v. I, p. 102-114, 1934.

DELISLE, Jean. Réflexions sur l'historiographie de la traduction et ses exigences scientifiques. Équivalences (ISTI, Bruxelles), vol 26, n. 2 et vol. 27, n. 1, p. 21-43, 1997 1998.

FECIORU, D. Bibliografia traducerilor în româneste din literatura patristica.

[Bibliographie des traductions roumaines de la littérature patristique]. v. I .Fascicola I: Epoca dela 1691 pâna la 1833. Bucuresti: Institutul de Arte grafice Bucovina, 1937.

GAFTON, Alexandru. De la traducere la norma literară. Contribuia traducerii textului biblic la constituirea vechii norme literare.[De la traduction à la norme littéraire]. Iași: Editura Universității «Al. I. Cuza» din Iași, 2012.

GHEŢIE, Ion ; MARES, Alexandru. Cele mai vechi cărţi populare în literatura. Floarea darurilor şi Sindipa română [Les plus anciens livres populaires roumains]. Bucureşti : Editura Minerva, 1996. 
GHEŢIE, Ion. Istoria limbii române literare [Histoire de la langue roumaine littéraire]. București : Editura Ştiinţifică şi Enciclopedică, 1978.

GIURGINCA, Ioana-Simina. Le discours traductologique in statu nascendi dans les préfaces des traducteurs roumains de français-source au XIXème siècle. Timisoara: Universitatea de Vest din Timisoara, mémoire de dissertation, 2012.

GRIMM, Petre. Scrieri de istorie literara [Écrits d'histoire littéraire]. Ediţie îngrijită, prefaţă, tabel cronologic şi notă asupra ediţiei de Liana Muthu. Cluj-Napoca: Eikon \& Scriptor, [1916-1943]2012.

HELIADE RĂDULESCU, Ion. Gramatica românească [Grammaire du roumain]. Ediţie şi studiu de Valeria Guţu Romalo. Bucuresti : Editura Eminescu, [1828]1980.

IORGA, Nicolae. Istoria literaturii româneşti din veacul al XIX-lea - de la 1821 înainte [Histoire de la littérature roumaine du XIXe siècle]. Bucureşti-Vălenii de munte :

Minerva/Tip. Neamul românesc, 1907-1909.

IORGA, Nicolae. Histoire des relations anglo-roumaines. Iași: Imprimerie „Progresul”, 1917.

IORGA, Nicolae. Traducerile din limba franceză în literatura românească [Traductions roumaines du français]. Vălenii de munte : Tipografia Datina românească, 1936.

ISAR, Nicolae. Opera şi ideile lui Simeon Marcovici. Autorul „retoricii” şi al traducerilor din literatura occidentala [L'œuvre et les idées de S. Marcovici - auteur du cours de rhétorique et des traductions de la littérature occidentale]. In: ISAR, N. Sub semnul romantismului. De la domnitorul Gheorghe Bibescu la scriitorul Simeon Marcovici. Bucuresti : Universitatea din Bucuresti, 2003.

IVĂNESCU, Gheorghe. Istoria limbii române. [Histoire de la langue roumaine] Iaşi : Editura «Junimea», 1980.

IVAŞCU, George. Istoria literaturii române. De la origini pana in prezent [Histoire de la littérature roumaine. Des origines à nos jours]. Bucureşti: Editura Ştiinţifică. 1969.

KOGĂLNICEANU, Mihail. Despre literatură [Sur la littérature]. Bucureşti : E.S.P.L.A., [1840-1844] 1956. Culegere, note şi cuvânt înainte de Dan Simonescu (p. 3-18).

LENZ, Hélène. La Traduction et la modernité littéraire. In: Centre d'Étude de l'Europe Médiane (ed.). Histoire de la traduction en Europe médiane. Paris: INALCO, 2011. Disponível em: http://histrad.info/index.php?option=com_content\&view =article\&id=365:latraduction-et-la-modernite-litteraire \&catid= 54:roumain $\&$ Itemid=85. Acesso em: 5 fev. 2013 .

LENZ, Hélène. La Traduction des textes religieux. In: Centre d'Étude de l'Europe Médiane (ed.). Histoire de la traduction en Europe médiane. Paris: INALCO, 2011. Disponível em: http://histrad.info/index.php?option=com_content\&view=category\&layout=blog\&id=54\&Ite mid=85. Acesso em: 18 mar. 2013. 
LENZ, Hélène. La Traduction et la formation de la littérature profane. In: Centre d'Étude de l'Europe Médiane (ed.). Histoire de la traduction en Europe médiane. Paris: INALCO, 2011. Disponívem em: http://www.histrad.info/langues/45-roumain/158-la-traduction-et-laformation-de-la-litterature-profane. Acesso em: 01 maio 2014.

LORÍA-RIVEL, Gustavo-Adolfo. Pentateuhul: probleme de traducere a textului biblic. [Le Pentateuque: problèmes de traduction]. Iași: Editura Universității « Al. I. Cuza » din Iași, 2004.

LOVINESCU, Eugen. Istoria literaturii române contemporane [Histoire de la littérature roumaine contemporaine]. v. I-V. Bucureşti: Editura Ancora Benvenisti, 1926-1929.

LUNGU-BADEA, Georgiana. Scurtă istorie a traducerii. Repere traductologice [Brève histoire de la traduction. Repères traductologiques]. Timișoara : Editura Universităţii de Vest, 2007.

LUNGU-BADEA, Georgiana. Rolul dicţionarelor în desăvîrşirea limbii şi a traducerii [Le rôle des dictionnaires dans l'achèvement de la langue et de la traduction]. In: LUNGUBADEA, G. (ed.). Un capitol de traductologie. Studii de istorie a traducerii (III). Timişoara: Editura Universităţii de Vest, 2008. p. 259-270.

LUNGU-BADEA, Georgiana. Le rôle des langues intermédiaires dans la réception de la 142 littérature française traduite en roumain au XVIIIe siècle. Tribune internationale des langues vivantes. Dossier: «Recherches en traductologie: Les langues intermédiaires», v. 51, p. 42-51, 2011.

LUNGU-BADEA, Georgiana. Idei și metaidei traductive românești (secolele al XVI-lea -al $\mathrm{XXI}-$ lea) [Idées et métaidées traductives roumaines $\left(\mathrm{XVI}^{\mathrm{e}}-\mathrm{XXI}^{\mathrm{e}}\right.$ siècles]. Timișoara: Editura Universităţii de Vest, [2013] 2015a.

LUNGU-BADEA, Georgiana. «Cine, ce şi cum traduce? Intenții. Subiecte. Metode» [Qui traduit? Quoi et comment traduit-on? Intentions, sujets; méthodes]. In: TIMOC C. (ed.).. Romània între interculturalitate şi identitate: Spaţii romanice europene şi extraeuropene. Szeged: University Press of Szeged, 2015b. p. 33-54.

LUNGU-BADEA, Georgiana. «Übersetzungsmethoden im Rumänischen im 18. und 19. Jahrhundert. Politische, sprachliche, ethische und ästhetische Problemstellungen». In: „Traducerile au de cuget să îmblînzească obiceiurile...". Rumänische Übersetzungsgeschichte - Prozesse. Produkte. Akteure. [éd.] M. Jeanrenaud, J. Richter et L. Schippel. Berlin : Frank \& Timme, 2014. p. 33-60.

LUPU, Coman. Lexicografia românească în procesul de occidentalizare latino-romanică a limbii române moderne (1780-1860) [La lexicographie roumaine et le processus de latinisation et de romanisation du roumain moderne (1780-1860)]. Bucureşti: Editura Logos, 1999.

MACEDONSKI, Alexandru. Opere II. Dramaturgie. Traduceri și adaptări în limba română. Versuri, proză, dramaturgie în limba franceză. [CEuvres II. Dramaturgie. Traductions et adaptations en roumain. Vers, prose, dramaturgie en français]. Édition soignée par M. 
Colojoară, préface d'Eugen Simion. București: Editura Fundației Naţionale pentru Știință și Artă, 2004

MUNTEANU, Eugen. Studii de lexicologie biblică [Études de lexicologie biblique]. Iaşi : Editura Universităţii «Al. I. Cuza», Iaşi, 1995.

MUNTEANU, Ştefan; ŢÂRA, Vasile. Istoria limbii române literare [L'histoire de la langue roumaine littéraire]. Bucureşti : Editura Didactică şi Pedagogică, [1978] 1983.

NICOLESCU, Aurel. «Observaţii asupra neologismelor din „Însemnare a călătoriei mele” a lui Dinicu Golescu»[Observations sur les néologismes chez D. Golescu]. In: NICOLESCU, Aurel. Contribuţii la istoria limbii române literare în secolul al XIX-lea. București : Editura Academiei R.S.R., Vol. II, 1958. p. 5-53.

PIRU, Al. Istoria literaturii române de la origini până la 1830 [Histoire de la litterature roumaine. Des origines jusqu'en 1830]. Bucureşti: Editura Ştiinţifică şi Enciclopedică, 1977.

PHILIPPIDE, Alexandru. Introducere în istoria limbei și literaturei romîne [Introduction à l'histoire dela langue et la littérature roumaine], Editura librariei Frații Saraga, 1888.

REISCHEL, Arthur. « Bibliografia traducerilor din literatura maghiara în limba româna » [Bibliographie des traductions roumaines de la littérature hongroise]. In: Sesiune ştiinţifică de bibliologie şi documentare: Comunicări şi discuţii. Volume 1. Bucuresti: Editura Academiei R.P.R., 1957. p. 67-68.

URSU, N. A. Formarea termenilor ştiinţifici românești [Formation des termes scientifiques roumains]. Bucureşti : Editura Ştinţifică, 1962.

URSU, N. A. «Şcoala de traducători români din obştea stareţului Paisie de la mănăstirile Dragomirna, Secu şi Neamţ» [L'École de traduction roumaine de Paisie, aux monastères de Dragomirna, Secu et Neamţ]. In: Teologie şi viaţa, v. VI (LXX), n. 11-12, p. 58-83, 1994.

URSU, N. A. Traducerile logofătului Toma Dimitriu de la Mitropolia din Iaşi [Les Traductions du chancelier Toma Dimitriou de l'Église Métropolitaine de Iaşi]. Almanahul Institutului de Istorie «A. D. Xenopol», v. XXXVI, p. 7-24, 1999.

\footnotetext{
* Georgiana LUNGU-BADEA - Doutora (2003) e Mestre (1992) em Literatura Francesa pela Universidade do Oeste de Timisoara. Professora titular da Universidade do Oeste de Timisoara, diretora da École doctorales en Sciences Humaines et Sociales (Faculté des Lettres, Histoire et Théologie) e professora visitante do Programa de Pós-Graduação em Estudos da Tradução (POSTRAD) da Universidade de Brasília. Universidade do Oeste de Timisoara, Faculté des Lettres, Histoire et Théologie, Département de langues. Universidade de Brasília, Programa de Pós-Graduação em Estudos da Tradução (POSTRAD) da Universidade de Brasília. Timisoara, Timis, Romênia. Brasília, Distrito Federal, Brasil.

Currículo acadêmico: https://litere.uvt.ro/wp-content/uploads/2014/07/03.CV_Georgiana_Lungu_Badea.pdf ORCID: https://orcid.org/0000-0002-0786-0412

E-mail: georgiana.lungu-badea@e-uvt.ro
}

** A tradução do artigo abaixo referenciado e sua publicação foram autorizadas por Georgiana Lungu-Badea, autora e editora-chefe do periódico acadêmico Translationes (ISSN $2067 \quad-\quad 2705$, https://translationes.uvt.ro/rt/fr/index.html). 
LUNGU-BADEA, Georgiana. Un regard sur les recherches roumaines en histoire de la traduction. Translationes, Timisoara, v. 7, 2015. DOI: 10.1515/tran-2016-0003

*** Natália Oásis de OLIVEIRA - Bacharel em Letras - Tradução Francês (2018) pela Universidade de Brasília. Mestranda em Estudos da Tradução na mesma instituição. Universidade de Brasília, Instituto de Letras, Programa de Pós-Graduação em Estudos da Tradução. Brasília, Distrito Federal, Brasil.

Currículo acadêmico: http://lattes.cnpq.br/0776722330371198

ORCID: https://orcid.org/0000-0002-1086-9506

E-mail: nataliaoasis@gmail.com

${ }^{1}$ Trata-se dos contatos internos não somente na Transilvânia e em Banat, mas também na Valáquia e na Moldávia onde instalaram-se ao leste, depois de 1789, franceses refugiados, preceptores, comerciantes etc. Mesmo reduzidos, os contatos com os ingleses que viajam nas províncias romenas, no século XIX, são levados em conta por ter contribuído para indicar os romenos aos ingleses (cf. Iorga 1917, M. Beza, English Travellers in Romania, 1920, apud. Grimm, 2012) e os contatos externos, estabelecidos por jovens romenos que foram estudar na França, na Itália e nas cidades do império do Habsburgo.

${ }^{2}$ Com a cultura, literatura e língua francesas, entre outros, por meio dos fanariotas gregos, oficiais e soldados russos etc.

${ }^{3}$ Ver também Dicționarul literaturii romane origens pînă a 1900 [Dicionário da literatura romena, desde as suas origens a 1900], Academia R.S.R., Universitatea Al. I. Cuza din Iaşi. Institutul de Lingvistică, Istorie Literară şi Folclor, 1979.

${ }^{4}$ Aqui destacamos apenas que alguns dos nomes dos historiadores suscetíveis a influenciar a pesquisa em História da Tradução: Al. Philippide 1888; E. Lovinescu 1926-1929; G. Călinescu 1941; G. Ivaşcu 1969; Ş. Cioculescu 1973.

${ }^{5}$ As listas de tradutores e traduções em romeno das línguas francesa, italiana e espanhola (RTR I e RTR II, 2006).

${ }^{6}$ ANGHELESCU, Mircea, Preromantismul românesc [O Pré-romantismo romeno]. Bucureşti: Minerva, 1971.

1447 Dictionarul romanului tradus în limba română [Dicionário do romance traduzido para o romeno] 2005. EMINESCU, Mihai. Teatrul original și tradus. Traducerile de proză literară. Dicționarul rime [Teatro original e traduzido. Traduções de prosa literária. Dicionário de rimas]. Volum îngrijit de Perpessicius. București: Fundația pentru Literatură și Artă "Regele Carol II", 1988.

${ }^{8}$ Trata-se de listas, dicionários, antologias, de biografias, bibliografias, iconografias etc.

${ }^{9}$ Em Lermontov, Editura Tineretului, Bucureşti, Colecția „Oameni de seamă”, 1963, Tamara Gane analisa as traduções romenas de Lermontov. O livro também contém uma lista das obras de Lermontov traduzido para a língua romena. Na esteira de Goes, Elena Cervinschi apresenta em seu livro, Lermontov în România [Lermontov na Romênia], em segundo lugar, Editura Minerva, 1987, a qualidade das traduções, as causas dos erros e seus efeitos sobre o leitor. O segundo volume das obras completas de Alexandru Macedonski traz traduções para o francês e oferece o tipo de informações explícitas sobre o interesse tradutivo do escritor.

${ }^{10}$ Ver LOGHINOVSKI, Elena. Eminescu în limba lui Puşkin [Eminescu dans la langue de Pouchkine], Iaşi, Junimea, 1989.

${ }^{11}$ Entre os autores mais traduzidos em romeno, encontra-se: A. France, Al. Daudet, Dumas pai, Fénelon, V. Hugo, G. Leopardi, P. Loti, G. de Maupassant, Molière, C. Mendes, G. Sand, E. Sue, Shakespeare e outros. Byron, Dante, Flaubert, Thomas Gray, Mérimée, Musset, Pétrarque, Al. Pope, Racine, Voltaire, Jovem, etc. estão sujeitos a traduções mais parcimoniosas; Diderot, Metastasis, traduções espaçadas (ver RTR II, 2006). Traduziu-se generosamente escritores obscuros, os tradutores compartilham o destino deles.

${ }^{12}$ Citamos apenas alguns nomes: Iorga 1907-1909; Puscariu [1920] 1989; Piru 1977; Gheţie 1978; Munteanu e Tara [1978] de 1983; Ivănescu 1980.

${ }^{13} \mathrm{O}$ interesse pela história da terminologia romena está crescendo. N. A. Ursu (1962); Coman Lupu (2000); Gheorghe Chivu, Limba română de la primele texte până la sfârșitul secolului al XVIII-lea. Variantele stilistice (2000); Mihaelei Marcu, Evoluția terminologiei gramaticale românești în perioada 1757 - 1877 (2005); Laura Elena Pascale, Terminologia lingvistică în primele gramatici românești (2011); Manuela Saramandu, Terminologia juridic-administrativă românească în perioada 1780 - 1850 (1986); Victor Vascenco, Probleme de terminologie lingvistică (1975), esses são apenas alguns títulos de uma lista mais longa. 